\title{
A Dialética Valores e Preços
}

\author{
The Dialectic Values and Prices
}

JOÃO ANTÔNIO DE PAULA"

\begin{abstract}
RESUMO: A maior parte do debate sobre o chamado "problema de transformação"; que deriva da crítica de Böhm-Bawerck ao terceiro volume do Capital, tem um quadro de referência que atribui pressupostos e uma metodologia a Marx mais adequada à teoria Walrasiana. Este artigo discute essa questão visando dois objetivos diferentes. Ele aponta as consequências problemáticas para a teoria marxista de valores e preços da aceitação dos pressupostos da abordagem do equilíbrio. Por outro lado, oferece um argumento para enfrentar o "problema de transformação" de um ponto de vista estritamente dialético.

PALAVRAS-CHAVE: Teoria do valor trabalho; problema da transformação.
\end{abstract}

ABSTRACT:Most of the debate about the so-called "transformation problem"; which stems from Böhm-Bawerck's criticism of the third volume of Capital, has a frame of reference that attributes presuppositions and a methodology to Marx that are more suitable to the Walrasian theory. This article discusses that question aiming at two different goals. It points the problematic consequences to the Marxist theory of values and prices of the acceptance of the presuppositions of the equilibrium approach. On the other hand, it offers an argument for tackling the "transformation problem" from a strictly dialectical point of view.

KEYWORDS: Labor theory of value; transformation problem.

JEL Classification: B52; D46.

\section{INTRODUÇÃO}

Hesito em enunciar o tema deste artigo. Há perigos envolvidos. O primeiro é que gere expectativas que, talvez, não sejam satisfeitas. Um outro risco é que induzirá o leitor menos benevolente a abandoná-lo no momento mesmo em que se enuncie seu conteúdo. Não há, neste caso, nem mesmo a possibilidade de reivindicar a "suspension of disbelief”. Não há atenuantes. O tema tem história longa, é centenário e controverso. Para muitos não há propósito em retomá-lo, porque, em

\footnotetext{
* Professor e pesquisador do Centro de Desenvolvimento e Planejamento Regional da Universidade Federal de Minas Gerais - CEDEPLAR/FACE/UFMG, Belo Horizonte/MG, Brasil. E-mail: jpaula@cedeplar.ufmg.br.
} 
seus termos básicos, está resolvido de um jeito ou de outro. Para estes, a questão foi resolvida com a demonstração da inconsistência definitiva de uma certa matriz conceitual. Retomar a questão a partir dessa matriz seria assim continuar prisioneiro de um fantasma. Diz Steedman: “La 'solución' del problema de la transformación ofrecido por Marx es por entero inaceptable; es internamente incoherente, aun cuando se transformen los precios de los insumos. [... ] Los economistas marxistas debieran dejar de perder el tiempo en debates incompetentes sobre sencillas cuestiones de lógica. Cuando se liberen del fantasma del 'problema de la transformación', quizá podrán dedicar sus energias al trabajo marxista importante”. (Steedman, 1985, p. 35).

Por algum motivo alguns marxistas se recusam a aceitar os bons conselhos e as propostas dos que acreditam já terem resolvido o problema. Talvez pela boa razão de que aceitar o que lhes oferecem os neo-ricardianos significa abrir mão da sua teoria do valor e com isso da base metodológico-analítica fundamental de sua teoria do capital e do capitalismo.

A chamada questão da "transformação dos valores em preços" teria tido início com a crítica de um certo Dr. Wolfgang Mühlpfort, logo após a publicação do Livro III de O Capital, em 1893. Nessa crítica, o Dr. Mühlpfort aponta suposta inconsistência no procedimento analítico de Marx - que ele deveria ter transformado também o capital constante e a variável em preços de produção - e terá grande recepção, além de ter sido o primeiro a buscar corrigir o procedimento de Marx. (Neto, 1997, p. 21).

Após a crítica pioneira do Dr. Mühlpfort, que passou despercebida, em 1896, o grande economista neoclássico, da Escola Austríaca, Bohm-Bawerk, publicará $A$ conclusão do sistema de Marx (1974 ), trabalho cujo centro é a busca da invalidação da teoria do valor de Marx, considerada de um lado desnecessária para a construção de uma teoria dos preços, e de outro lado inconsistente como base para uma teoria dos preços.

À provocação de Eugen von Bohm-Bawerk se seguirá a tentativa insuficiente de resposta de Rud olf Hilferding (1974), de 1904, e a pseudo-efetiva solução de Bortkiewicz (1974), apresentada em trabalhos de 1906 e 1907. O conjunto desses trabalhos foi reunido em volume, que, com introdução de Paul Sweezy, foi publicado em 1974, pelos Cuadernos Pasado y Presente, com o título - Economia Burguesa y Economia Socialista.

Neste artigo, o tema da transformação dos valores em preços será retomado na medida em que é uma questão importante para o desenvolvimento do pensamento marxista, isto é, que o correto enquadramento e enfrentamento do problema reafirma a acuidade teórico-analítica do marxismo.

Fundamentalmente, a tese que se vai defender aqui é que a tradição da polêmica sobre a " transformação", isto é, a busca de um método que estabeleça a passagem dos valores aos preços, como se estes constituíssem dois momentos isolados da dinâmica capitalista, criou um problema inteiramente desfocado, cujas soluções ou levam ao abandono da teoria do valor ou à reafirmação de uma pretensa ortodoxia marxiana. Pretende-se apresentar aqui um argumento que busca 
enfrentar o problema a partir da afirmação do que é rigorosamente fundamental em Marx, que é a centralidade da dialética como método e como ontologia. Isto é, enfrentar a questão não mais no plano da afirmação da identidade, nos marcos de uma perspectiva de equilíbrio geral, mas no terreno em que a contradição é o móvel e o conteúdo do processo de determinação dos preços no regime capitalista. Significa, enfim, dizer que não há um "problema de transformação" , mas uma dialética na relação entre valores e preços.

Entre os muitos mistérios que assombram e perturbam a trajetória do marxismo, um é particularmente intrigante. Como, por quase cem anos, o marxismo não se deu conta de que, ao tentar responder à tentativa de invalidação de Bohm-Bawerk, a partir da "solução" de Bortkiewicz, fez entrar e instalar-se, confortavelmente, em seu campo teórico, uma teoria e um método walranianos, que lhe são inteiramente estranhos e incompatíveis?

Para muitos marxistas, é certo, isto, na verdade, nunca foi problema porque sempre viram Marx como apenas mais um economista, melhor em alguns aspectos que outros economistas, dotado de perspectiva ético-ideológica superior, mas, ao fim e ao cabo, um economista. Ora, nesse sentido, aceitar os termos do debate tal como proposto por Bohm-Bawerk/Bortkiewicz é, até, positivo, na medida em que mostra que os marxistas também são capazes de formalizar seus conceitos.

Contudo, a grande questão decorrente dessa invasão walraniana é colocar o marxismo a reboque de uma perspectiva teórica, de pressupostos e implicações radicalmente incompatíveis com o central de sua proposta teórico-metodológica. É o que está amplamente discutido no livro organizado por Alan Freeman e Guglielmo Carchedi, em 1996, Marx and Non-Equilibrium Economics.

Este ensaio, talvez correndo o risco de certo exotismo, é uma reafirmação da atualidade e vitalidade do marxismo e uma recusa à rendição teórica e política que os vitoriosos de hoje estão exigindo de nós enquanto fazem negócios e barbárie.

\section{RECOLOCANDO A QUESTÃO}

Na contestada solução de Marx ao "problema da transformação", o mais recorrente dos argumentos é quanto ao caráter incompleto da "transformação" operada ali, que teria deixado de fora a transformação dos insumos. Para resolver essa inconsistência, as soluções, a partir de Bortkiewicz (1906, 1907), passaram a adotar o procedimento de determinação simultânea de valores e preços mediante a montagem de sistema de equações simultâneas em que é explícita a inspiração walrasiana. Nesses procedimentos, a presença de Walras é mais que uma inspiração de um método algébrico. É uma exigência teórica forte, o equilíbrio geral, que contrabandeado para o marxismo levou, entre outros aspectos, a equívocas interpretações dos esquemas de reprodução de Marx, como nos mostrou Rosdolsky (1978, cap. 2, apêndice II).

Contudo, para o argumento que se vai desenvolver aqui, o essencial é lembrar que se o expediente da determinação simultânea de preços e valores mediante sis- 
tema de equações tem eficácia matemática, do ponto de vista das determinações reais, ele é uma simplificação destituída de sentido, sem nexos reais, sem causalidades históricas, e que, sobretudo, interdita a sequência material de atos de compra e venda, que marca o processo de formação dos preços e que está posto em toda a cadeia de interações que marca o processo da produção à realização.

O que está implícito no ciclo do capital-dinheiro descrito por Marx - D - M... P ... M' - D' - é a intercorrência de diversos atos de compra e venda no processo mesmo de produção, o que significa dizer que a relação entre produção e circulação não pode ser considerada uma sequência lógico-histórica rígida, mas momentos interagentes e articulados do mesmo processo global: a produção e reprodução capitalista. Assim o dinheiro, D, que dá origem ao processo de produção, compra meios de produção, MP, e aluga Força-de-Trabalho, FT, atos que estabelecem de imediato a conexão entre a produção e a circulação, e que explicitam a existência de preços dados, isto é, o mercado de capital constante e o mercado de força de trabalho. A seguir, esses elementos são organizados no Processo de Produção, P, o qual, ao final, gerará um conjunto de mercadorias, M', que vendidas, possibilitarão ao capitalista recuperar o dinheiro inicial que colocou no processo, D, e que foi usado para comprar MP e FT, e mais um lucro, resultante da mais valia, m, extraída da exploração da FT. Esquematicamente:

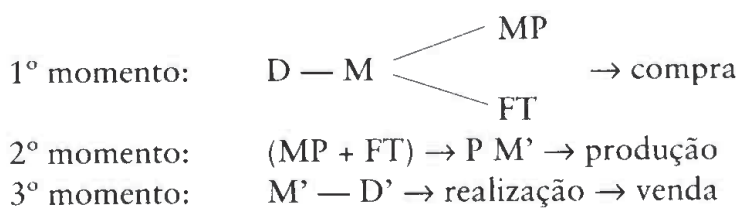

Então, o processo de produção capitalista, isto é, o processo de produção que visa o lucro, é o resultado de atos que se dão articuladamente nos planos da produção e da circulação. Nesse sentido, não há propósito em estabelecer a "determinação dos preços como uma sequência lógica em que primeiro são definidos os valores (plano de produção), que em seguida serão levados ao mercado (plano de circulação) para a aferição social dos valores, isto é, para a determinação dos valores efetivamente sancionados socialmente.

$\mathrm{Na}$ verdade, o processo de determinação dos preços resulta de uma série sistemática de interrelações alternadas entre o plano de produção e da circulação, entre valores e preços. $\mathrm{O}$ processo inicia-se com um conjunto de preços dados - o preço do capital constante; os salários; os juros; o aluguel; o lucro esperado - e é a avaliação desses preços que determinará a forma da produção. Nesse sentido, quando os capitalistas iniciam o processo de produção, estão cientes do conjunto de preços relevantes e só tomam a atitude de produzir porque consideram viável o negócio dados aqueles preços. O que é, então, incógnita nesse processo, que se inicia com o conhecimento, pelo produtor, das condições de mercado? São incógnitas os elementos mesmo da concorrência: as modalidades concretas de extração da mais valia operadas pelos outros capitalistas; a dinâmica do progresso tecnológico; a "politização" dos preços decorrente da ação do Estado; a entrada de novos 
capitalistas no ramo de produção considerado; as modificações no gosto e na preferência dos consumidores ...

Nesse sentido, a determinação dos preços, do ponto de vista da teoria marxista, deve inicialmente abandonar um pressuposto que, até aqui, tem balizado todas as abordagens referentes ao chamado "problema da transformação dos valores em preços". Trata-se, no fundamental, de superar o procedimento padrão que reduz a questão a um puro exercício de determinação simultânea de preços e valores. Nesse caso, como sempre, é essencial ter em conta que a teoria marxista é uma ontologia social, o que significa dizer que qualquer procedimento analítico nesse campo tem sua validação na medida em que toma a realidade material como seu ponto de partida. Isso significa tomar a realidade como conjunto de atos concretos, historicamente determinados e determinantes.

Um outro aspecto essencial do procedimento analítico genuinamente marxista, que é preciso construir no referente à determinação dos preços, é entender o processo não como lógica da identidade mas como dialética, isto é, como ontologia, contradição e alteridade.

\section{O QUE DE NOVO ESTÁ DITO AQUI}

Em 1996 apareceu o livro Marx and Non-Equilibrium Economics, organizado por Alan Freeman e Guglielmo Carchedi, que serve, para o texto que se vai ler aqui, apoio implícito e reiteração de uma mesma recusa à perspectiva proto-walrasiana, que penetrou muitas das tentativas no campo do marxismo no referente à relação entre valores e preços. Mais recentemente, João Machado Borges Neto, em sua Dissertação de Mestrado - "A Transformação dos Valores em Preços de Produção em um Sistema Único Temporal”, de 1997, e em artigo para a Revista ANPEC, no. 3, de 1998, cujo título é "O Sistema Único Temporal: uma Nova Abordagem da Transformação dos Valores em Preços de Produção”, sistematizará o fundamental dos esforços coletivos centrados na busca de uma alternativa marxista não-walraniana à "questão da transformação".

A base desses esforços é a construção de um sistema chamado único temporal, que, rejeitando o dualismo metodológico introduzido por Bortkiewicz $(1906,1907)$, para estabelecer a transformação dos valores em preços, perpassa grande parte do que se disse sobre o tema desde então. Esse sistema único temporal teria como característica básica ser não-dualista e introduzir, efetivamente, o tempo, isto é, a sequência real-cronológica de fatos, de que é feita a economia como dimensão central do processo. A rejeição da pseudo-solução da determinação simultânea de valores e preços, que marca o tema de Bortkiewicz a Sraffa, implica fundamentalmente considerar a relação entre valores e preços como um processo real, como ontologia, onde o valor não é apenas relação de troca, mas substância social, produzida pelo trabalho abstrato e redistribuído entre os vários capitais, sob a forma de mais valia, resultando daí a diferenciação entre valores e preços que é constitutiva, fundante, razão de ser mesmo do próprio movimento do capital. 
João Machado Borges Neto mostra em seus trabalhos citados como foram sendo gestadas formulações alternativas à transformação dualística. Em primeiro lugar, o chamado "método iterativo de cálculo", que, iniciando-se com Shibata em 1933, floresceu nas décadas de 1970 e 80 com os trabalhos de Brody, Okishio, Shaikh, Morishima, Catephores, Panizza e Pala (Neto, 1997, p. 52).

Uma segunda corrente, chamada new solution, new approach ou new interpretation, que se inicia na década de 1980 , teve as contribuições decisivas de Duménil, Lipietz, Duncan Foley, Glick, Erbahr, Simon Mohun (Neto, 1997, p. 53).

A terceira corrente buscou construir um sistema que é chamado de sistema único simultâneo; inicia-se também na década de 80, com, entre outros, os trabalhos de Wolff, Callari e Roberts, Fred Moseley e Ramos e Rodriguez (Neto, 1997, pp. 54-5).

Finalmente, a quarta corrente é a que aborda o tema do ponto de vista do sistema único temporal; que também tem início na década de 1980 e tem como trabalhos pioneiros os de Kliman e McGlone, Freeman, os diversos textos do livro já citado e organizado por Freeman e Carchedi, além dos trabalhos de Perez, Ernst, Langston, Maldonado Filho, além dos trabalhos do próprio João Machado Borges Neto (Neto, 1997, pp. 56-8).

Todo esse inventário visa, de um lado, mostrar a atualidade e vivacidade do tema, de outro, situar o específico do trabalho que se está lendo.

A questão central é a seguinte: tudo o que será dito aqui, não é, de forma alguma incompatível com a abordagem do sistema único temporal. Contudo, reivindica-se, talvez imodestamente, certa originalidade no que se propõe. Trata-se da afirmação de um princípio metodológico que, se está implícito em muitos dos trabalhos considerados, não teve qualquer função heurística explícita nas abordagens - enfim, trata-se de afirmar a centralidade da dialética como método e como ontologia do ser social.

Vários autores - Lukács, Rosdolsky, Kosik -, em abordagens seminais, insistiram no inescapável da dialética da obra de Marx. No entanto, muito poucos, de fato, conseguiram extrair as consequências necessárias disso, que, quase sempre, transformou-se numa petição de princípio vazia de conteúdo. Afinal, o que significa ser dialético, como apresentar os resultados de uma pesquisa de forma dialética?

São, como se sabe, questões complexas. Incidindo diretamente sobre o tema em pauta comecemos por uma lição de Lukács: "Creio, então, que o caminho que devemos empreender, e com o qual já entramos de cheio nos problemas ontológicos, é o da pesquisa genética. Isto é: devemos tentar pesquisar as relações nas suas formas fenomênicas iniciais e ver em que condições estas formas fenomênicas podem tornar-se cada vez mais complexas e mediatizadas" (Lukács, 1969, p. 13).

$\mathrm{E}$ as formas fenomênicas iniciais aqui não são os valores, como imagina certa falsa ortodoxia marxista. A forma fenomênica inicial aqui é a mercadoria. É isto que Marx disse, explicitamente, em seu último texto econômico, de 1882, "Glosas marginais ao Tratado de economia política de Adolph Wagner" - "El señor Wagner olvida también que para mi no son sujetos ni el 'valor' ni el 'valor de cambio', sino que lo es solamente la mercancia” (Marx, 1977, p. 171 ).

Tomando a mercadoria em sua realidade física e social, o fato de existir no 
mercado, de ser a coagulação do trabalho humano, de ter um preço, é daí que a crítica da economia política parte, sendo a sua trajetória o processo de constituição das mediações que transformaram a mercadoria, "de unidade elementar da riqueza", em capital, isto é, "coleção de mercadorias, conjunto da riqueza nas sociedades onde rege a produção capitalista”, como está dito na primeira frase de O Capital.

Então, o que é decisivo na relação entre valores e preços, do ponto de vista marxista, não é o estabelecimento de uma falsa anterioridade dos valores a que se segue um conjunto de preços correspondentes, cabendo à teoria a irrealizável tarefa de encontrar um "método de transformação" que garanta a identidade entre valores e preços. Tal procedimento é absolutamente estranho às preocupações de Marx e só tem solução, como mostrado por Sraffa, com o abandono da teoria do valor como substância social.

Desse modo, este artigo tem como objetivo central mostrar a mecânica real da relação entre valores e preços mediante a reivindicação de seu caráter dialético, a qual se concretiza pela explicitação de três aspectos centrais que distinguem o argumento que se segue das outras abordagens do tema. O primeiro aspecto é o referente à forma triádica da relação entre valores e preços. Ao contrário da usual apresentação do problema, que reduz a questão ao dualismo: valores valores preços, o que se diz aqui é que a relação é, na verdade: preços valores preços. Isto é, todo o processo tem origem com preços, os quais são dados, esses preços são as referências que vão balizar as condições concretas da produção e desse modo a conservação dos valores já criados e a criação de novos valores, os quais se expressarão novamente como preços, no momento da venda da mercadoria produzida, o que, adaptando-se à fórmula do ciclo do capital-dinheiro, seria:

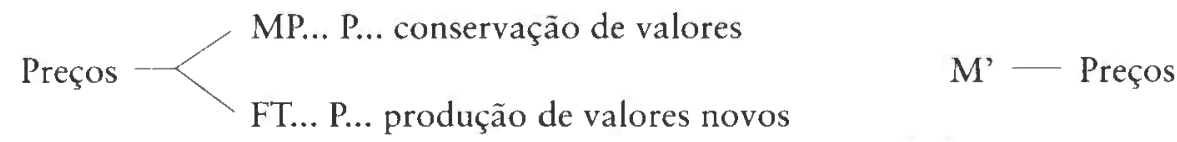

O segundo aspecto sobre o qual se reivindica a originalidade da apresentação é no referente à relação entre as esferas da produção e da circulação. A apresentação padrão estabelece, coerente com o que foi visto na relação entre valores e preços, a dualidade: produção circulação. Ora, essa anterioridade da produção em relação à circulação é tanto lógica quanto empiricamente sem sentido. Tanto a produção capitalista como sistema, quanto o capital como categoria lógico-genética têm como ponto de partida a circulação; o que significa que o circuito da interação entre produção e circulação é, na verdade, o seguinte: circulação $\rightarrow$ produção $\longrightarrow$ circulação.

Finalmente, o terceiro aspecto sobre o qual se reivindica originalidade é que as duas tríades anteriores (preços valores $\rightarrow$ preços e circulação $\rightarrow$ produção $\rightarrow$ circulação) estão inter e intra articuladas. Isto é, mudanças tanto nas condições de produção quanto nos mercados determinam mudanças nas formas concretas de extração da mais valia e nas estratégias concorrenciais. De tal modo que as duas tríades articuladas teriam a seguinte fórmula: 


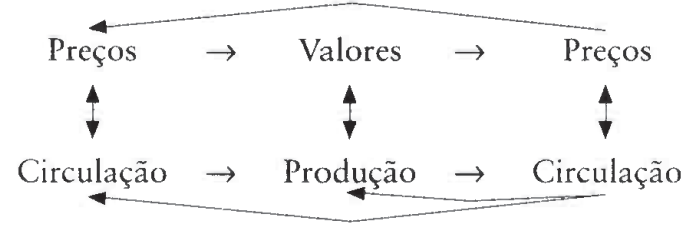

O que significa dizer que os capitalistas, de posse das informações de mercado, buscam a cada momento tanto adequarem suas estratégias competitivas, quanto seus relacionamentos com fornecedores e clientes, e, sobretudo, suas políticas de salários, organização do trabalho e inovações tecnológicas, de tal modo que, de fato, há uma permeabilidade permanente entre as esferas da circulação e da produção.

Isto significa que os preços que os produtores em princípio "tomam" no mercado definem as estratégias de produção desses mesmos produtores, as formas concretas como vão organizar a extração da mais valia e como vão se apresentar competitivos no momento da venda de seus produtos. Assim, o preço de venda das mercadorias é o resultado de um processo permanente de interação entre as esferas da circulação e produção, em que os preços de compra de matérias-primas e os salários pagos, o desgaste do capital constante utilizado, que são quantidades de dinheiro, terão que ser conservados-ampliados no processo de produção, possibilitando, assim, que, pela venda, a quantidade de dinheiro dispendida seja aumentada.

\section{A DIALÉTICA DA RELAÇÃO ENTRE VALORES E PREÇOS}

Mais de uma vez, quando o objetivo era analisar a gênese histórica do capital, Marx lembrou-nos que o ponto de partida, a forma inicial, história e logicamente, do capital é a circulação - "A circulação das mercadorias é o ponto de partida do capital” (Marx, 1968, livro I, cap. N, p. 165).

O interessa aqui é afirmar a anterioridade histórica e lógica da esfera da circulação e todas as consequências disso para o processo de determinação dos preços. A circulação, isto é, a existência dos mercados de dinheiro, de produtos, de força de trabalho e seus preços, é um dado desde o início do processo de produção. $\mathrm{O}$ processo só será iniciado se o capitalista avaliar, com base nos sinais do mercado, a viabilidade a priori do negócio. A circulação, isto é, os mercados e os preços, estabelece os marcos abstratos, os elementos capazes de induzir, ou não, o investimento. Então, já desde o início, estão dados certos preços, não havendo propósito, senão os decorrentes da utilização de um sistema de equações simultâneas, em afirmar que os preços serão determinados ao mesmo tempo que os valores, ou as quantidades físicas de mercadorias. Alguns preços antecedem, lógica e historicamente, a produção.

Então, se o capitalista, dada uma estrutura de preços, resolve produzir, é porque ele acredita que, independentemente de sua posição relativa na indústria, ele tem condições, no processo de produção, de se afirmar no mercado, obter lucros 
etc. Essa crença, baseada no seu conhecimento e experiência, e, sobretudo, nos elementos de sua própria estrutura produtiva, significa que o processo de produção, que ele fará deslanchar, é capaz, a priori, de garantir a lucratividade mínima do empreendimento. Tudo então, a partir daí, vai se passar no interior da unidade produtiva de forma a buscar sancionar o lucro esperado pelo capitalista.

Rigorosamente, do ponto de vista lógico-genético, a circulação, os dados preliminares do mercado, a compra de capital constante e variável, é a tese, momento abstrato do processo de produção do capital, que terá que ser materializada, mediante o processo de produção que aparece, assim, como antítese. Nesse processo, reinam, sobretudo, as estratégias concretas da apropriação da força de trabalho pelo capital, as formas concretas da extração da mais valia, que estarão calibradas em função dos sinais de mercado, dos preços pagos pelo capital constante, dos salários, do preço do produto no mercado, da tecnologia disponível. No interior da produção, o capitalista tentará superar sua eventual inferioridade tecnológica em relação a seus concorrentes mediante o aumento da exploração do trabalho, fundamentalmente. Nesse sentido, a esfera da produção, o processo de produção que se segue à circulação, é sua complementação necessária e sua negação. A produção, o processo de extração de mais valia significam a transformação — metamorfose — destruição — recriação do capital constante e variável em mercadoria, que terá que conter, além do valor dos custos de produção $(\mathrm{C}+\mathrm{V})$, o lucro do capitalista.

Contudo, esse momento, em que a matéria do capital constante foi transformada, que o capital variável foi posto em ação e tanto conservou o valor do capital constante quanto criou o seu próprio valor e um valor excedente, esse momento crucial do processo de produção capitalista ainda não é o que o realiza definitivamente. Há ainda um outro, a síntese, tão essencial quanto os anteriores, que é o da venda das mercadorias produzidas, a volta à materialidade do mercado das novas mercadorias produzidas, e que, de novo na circulação, confrontar-se-ão com as outras mercadorias produzidas pelos concorrentes.

Neste ponto, é importante lembrar que entre o D inicial e o D' final da realização, há descontinuidade espacial e temporal, o que significa dizer que tanto as condições de mercado, a demanda e a oferta, quanto as outras dimensões da concorrência poderão ter sofrido alterações, invalidando ou reforçando as iniciativas dos capitalistas no plano da produção. Trata-se, nesse sentido, da síntese do processo, isto é, da reunião dos momentos da circulação inicial e da produção, na realização. Busca-se, aqui, construir argumento baseado na ideia de que a dinâmica concorrencial é, imediatamente, intra-setorial, isto é, são os capitalistas de um mesmo ramo industrial que efetivamente travam a competição. Contudo, é preciso ter claro que o processo competitivo efetivo, só se completa com a concorrência inter-setorial. Também suposto aqui que a concorrência terá os seus limites e possibilidades de transferência intra-setorial de mais valia dados pela diferença entre o produtor mais eficiente e o mais ineficiente. $\mathrm{Na}$ base dessa interação, está a ideia de que todas as tentativas que o produtor ineficiente fizer para se manter no negócio, aumentando a mais valia do ponto de vista absoluto e/ou relativo, pagando salários abaixo do valor da força-de-trabalho, reduzindo os preços pagos pelo 
capital constante, todos esses expedientes acabam por ter efeito para o conjunto da economia na medda em que são todos mecanismos que contribuem para o aumento da mais valia global, na medida em que reduzem, numa certa proporção, os custos de reprodução da força de trabalho, e acabam assim, afinal, por beneficiar ainda mais os produtores mais eficientes que, nesse caso, se beneficiariam com os expedientes desenvolvidos pelos produtores mais ineficientes, sobretudo quando desenvolvem estratégias que acabam por baixar a taxa de salários etc...

Trata-se, então, de admitir uma permanente transferência intra-setorial e inter setorial de mais valia na medida mesmo da existência de diferenças significativas entre as estruturas produtivas.

É costume tomar o capítulo IX do livro III de O Capital como o locus privilegiado da discussão sobre a questão da relação entre valores e preços. Durante muito tempo, esstas leituras, de Bortkiewicz a Sweezy, resultaram em aprisionar o problema ao esquadro walraniano. Mais recentemente, como já foi dito, os autores do sistema único temporal mostraram como é possível afirmar a perspectiva efetivamente marxista da questão a partir do mesmo capítulo IX.

Como também já se disse aqui, nada há que objetar, do ponto de vista do argumento que se desenvolve aqui, às contribuições das teses do sistema único temporal, que apresentam solução rigorosa do ponto de vista formal e da fidelidade à perspectiva marxista.

Contudo, é no capítulo X do livro III que Marx amplia o argumento referente às relações entre valores e preços, para incorporar questões de que não tratará completamente, mas que têm enorme importância para os que vêem no marxismo um instrumento heurístico atual. Trata-se da não desenvolvida "teoria da concorrência" que Marx planejou construir em livro que jamais foi escrito. Reportando-se a essa questão, Roman Rosdolsky cita Marx e conclui: "En uno de los últimos capítulos del libra III puede lerse a este respecto: 'Exponiendo cómo las relaciones de producción se reifican y se hacen autónomas frente a los agentes de la producción, no examinamos la manera en que las relaciones tales como: el mercado mundial, sus coyunturas, el movimiento de los precios corrientes, los períodos de crédito, los ciclos de la industria y el comercio, la prosperidad y la crisis alternativamente, aparecen ante ellos como otras tantas fuerzas naturales, aplastantes y despiadadas, que les dominan y les parecen representar una necesidad ciega'.

“Tales son los problemas que Marx reservó para una 'continuación eventual' y que solamente trató en El Capital de manera fragmentaria o en conexión con otros temas. A nuestro parecer, los problemas más importantes son los del mercado mundial, las crisis económicas y 'el movimiento real de los precios' (que Marx declaró expressamente que queria enlazar 'con una investigación particular sobre la competencia') ". (Rosdolsky, 1972, p. 234).

Embriões dessa teoria da concorrência encontram-se no capítulo X, texto que incorpora, de forma rica e flexível, vários elementos que devem compor uma 
teoria de concorrência real, isto é, dos vários capitais, das contradições entre eles, da presença da oferta e demanda como participantes do processo global da formação dos preços.

\section{ASPECTOS QUANTITATIVOS DA RELAÇÃO ENTRE VALORES E PREÇOS}

A lógica do argumento que se defende aqui está baseada em dois princípios:

1) $\mathrm{Na}$ necessidade de se levar a sério o método dialético também no referente à relação entre valores e preços; e 2) na compreensão da realidade econômica como totalidade histórica concreta, isto é, como realidade complexa e contraditória em sua dinâmica.

Nesse sentido, os esquemas analíticos quantitativos que serão expostos a seguir devem ser entendidos como aproximações simplificadoras de uma realidade em constante mutação, onde não há lugar para identidades e equilíbrios como metas e princípios.

A mecânica de construção dos esquemas quantitativos que se vai apresentar difere dos esquemas tradicionais na medida em que tenta reproduzir a marcha real dos diversos momentos do processo de produção capitalista, o que significa admitir a interação-alternância entre os planos da circulação e de produção, a partir da sequência circulação-produção-circulação, e entre valores e preços a partir da sequência preços-valores-preços.

Admita-se, em primeiro lugar, uma indústria onde existam três empresas, A, B, C, com as composições orgânicas do capital diferentes, responsáveis respectivamente por $20 \%, 60 \%$ e $20 \%$ da oferta, e equilíbrio entre oferta e demanda. Isso significa dizer que, nesse caso, o produtor B será o produtor modal, isto é, definirá os parâmetros básicos, da oferta, o preço de produção que vai ser assim o preço do mercado. Admita-se também que o produtor A detém tecnologia superior utilizando-se de equipamentos e materiais auxiliares mais avançados, pelos quais pagou $60 \$$ aos quais associou trabalhadores, que deverão receber salários no valor de $40 \$$. O produtor B pagou $50 \$$ pelo capital constante que vai utilizar e pagará $50 \$$ em salários. Finalmente o produtor C pagou $40 \$$ pelo capital constante e pagará $60 \$$ de salários, tendo tecnologia inferior.

Marx expressa essta situação da seguinte maneira: "Admitamos que a grande massa dessas mercadorias se produza aproximadamente em condições sociais normais, de modo que esse valor seja ao mesmo tempo o valor individual de cada uma das mercadorias que constituem essa massa. Se há duas frações menores, uma produzida abaixo, outra acima dessas condições, de modo que o valor individual de uma é maior, e o da outra menor que o valor médio dessa massa central, os dois extremos se compensam, de modo que o valor médio das mercadorias nela situadas é igual ao valor das mercadorias da fatia do meio, e assim o valor de mercado fica determinado pelo valor das mercadorias produzidas em condições médias". (Marx, 1974, p. 206).

Além dos preços dados, também são conhecidos o preço de mercado do produto, os juros e os aluguéis. É a partir desses preços que os capitalistas, os produ- 
tores A, B e C, colocarão em marcha o processo de produção. Para cada nível de preço do produto e para cada nível da taxa de juros, os produtores, em função de sua estrutura técnica da produção e das relações concretas de dominação do trabalho, adotarão estratégias que implicarão em tentativas de renegociar preços de capital constante, salários, juros e aluguéis, redefinição da jornada de trabalho, esforço de venda, busca de subsídios, incentivos e proteção etc. Contudo, a grande e fundamental estratégia que os produtores podem adotar é a alteração das formas concretas de extração da mais valia. É sobretudo nesse plano, no domínio concreto do capital sobre a força de trabalho, que as eventuais debilidades tecnológicas de um produtor poderão ser compensadas pelo aumento da exploração do trabalho. Nesse caso, o preço tende a ser fixado pelo produtor modal B, o que significa dizer que o preço será fixado num nível que cobre os custos de produção $(\mathrm{C}+\mathrm{V})$ mais o lucro do produtor $(\mathrm{M})$. Esse lucro é produto de extração de trabalho não pago à Força de Trabalho. A taxa de exploração da Força de Trabalho, a taxa de mais valia, vai depender, em cada caso, do preço de mercado do produto, da estrutura técnica da produção, da etapa vigente do ciclo econômico, da política de Estado e do grau de organização dos trabalhadores.

Admita-se que o produtor B fixe sua taxa de exploração em $100 \%$, isto é, que obtenha $50 \$$ de lucro. Nesse caso, o preço de mercado do produto será igual a 150 . Nesse caso, restará aos produtores A e C se adaptarem ao preço de mercado, o que implicará no caso de C, para se manter competitivo, aumentar sua taxa de mais valia e/ou reduzir os salários. Quanto ao produtor A ao vender seu produto ao preço do mercado, 150, se apropriará de um lucro extraordinário de 10.

Contudo, não é essa a dinâmica real da determinação dos preços. O exposto acima, na verdade, estabelece uma condição irreal, que é o equilíbrio estático, onde cada produtor se contentaria com uma fatia de mercado dada e irremovível. $\mathrm{Na}$ realidade da dinâmica capitalista, todos os três produtores procurarão aumentar seus lucros seja por meio da redução de seus custos, seja pela ampliação de suas participações no mercado. Todos esses objetivos estão, em última instância, vinculados à capacidade dos capitalistas em aumentarem suas taxas de mais valia.

De qualquer modo, na situação anterior, não há qualquer propósito em aceitar que o produtor mais ineficiente se beneficie disso. $\mathrm{Na}$ verdade, esse produtor, por estar produzindo em condições inferiores à moda, será penalizado na medida em que estará dispendendo um tempo de produção superior ao que é socialmente necessário e que é definido pelo produtor modal, nas condições de equilíbrio entre oferta e demanda. Assim, na verdade, o produtor C, ao ter um custo de produção superior ao do produtor B, terá uma redução em seus lucros na proporção da diferença entre seu custo de produção e o do produtor B.

Contudo, o processo não se encerra aí. De posse deste dado objetivo, a diferença entre seu preço de produção $(\mathrm{C}+\mathrm{V}+\mathrm{M}=160 \$)$ e o preço de mercado, que no caso aqui é igual ao preço de produção do produtor B, isto é, $150 \$$, o produtor $\mathrm{C}$ poderá desenvolver uma estratégia de permanência na indústria mediante o aumento de sua mais valia sob a forma absoluta (aumento da jornada e/ou intensificação da jornada de trabalho) ou mesmo pela redução dos salários. Tais estratégias, na verdade, acabarão beneficiando os produtores A e B na medida em que o au- 
mento da mais valia do produtor C significará redução, em algum grau, dos custos gerais de reprodução da força de trabalho e/ou redução dos salários.

O que está implícito na argumentação usada nesse e nos outros casos que vão se seguir é que o mecanismo concorrencial, que significa em muitos casos a transgressão da troca de equivalentes, o pagamento de salários abaixo do valor, por exemplo, atua, decisivamente, na transferência da mais valia entre os capitais, isto é, na determinação da taxa média de lucro, a partir de valores individuais e taxas de mais valia diferenciadas.

Trata-se de lembrar capítulo quase sempre esquecido na discussão sobre a dinâmica da acumulação, que é o XXII do livro I, que se chama "Transformação da mais valia em capital", em que Marx estuda as diversas formas concretas de extração da mais valia que não a forma por excelência tipificada no capítulo XXIII, do livro I - “Lei Geral de Acumulação Capitalista”. É no capítulo XXII que Marx dirá: “A redução compulsória do salário abaixo desse valor, entretanto, na prática desempenha papel demasiadamente importante para não nos determos por um momento em sua análise. Dentro de certos limites, essa redução transforma efetivamente o fundo de consumo necessário à manutenção do trabalhador em fundo de acumulação de capitais”. (Marx, 1968, p. 697).

Ou seja, não há que se desdenhar o papel decisivo, dentro de certos limites, de formas não-canônicas de apropriação de lucros. Na verdade, no concreto da concorrência, os capitais estão, o tempo todo, na fronteira da delinquência, em vários sentidos, onde tanto a lei do valor, quanto a lei moral ficam sob ameaça.

A tentativa do produtor $\mathrm{C}$ de se manter na indústria pode acabar por beneficiar os produtores mais eficientes, instituindo-se, efetivamente, um processo de transferência de mais valia dos setores mais atrasados para aqueles de tecnologia superior, se essa tentativa resumir-se a aumentar a mais valia absoluta ou buscar reduzir salários. Salários menores pagos num setor podem acabar por reduzir a taxa geral de salários para o conjunto da economia.

Numa visualização esquemática:

Quadro I: Equilíbrio entre oferta e demanda

\begin{tabular}{c|c|c|c|c|c|c|c|c|c}
\hline & \multicolumn{3}{|c|}{ Circulação } & \multicolumn{3}{c|}{ Produção } & \multicolumn{2}{c}{ Circulação } \\
\hline Produtor & Preço inicial & C & V & M & PP & ME & MT & P.M. & TL = MT \\
\hline A & $150 \$$ & $60 \$$ & $40 \$$ & 40 & $140 \$$ & +10 & 50 & $150 \$$ & $50 \%$ \\
B & $150 \$$ & $50 \$$ & $50 \$$ & 50 & $150 \$$ & - & 50 & $150 \$$ & $50 \%$ \\
C & $150 \$$ & $40 \$$ & $60 \$$ & 60 & $160 \$$ & -10 & 50 & $150 \$$ & $50 \%$ \\
$\Sigma$ & $450 \$$ & $150 \$$ & $150 \$$ & 150 & $450 \$$ & 0 & 150 & $450 \$$ & \\
\hline
\end{tabular}

onde:

Preço inicial $\longrightarrow$ é o preço vigente no mercado no momento da decisão do investimento

$\mathrm{C} \rightarrow$ preço do ca pital constante

$\mathrm{V} \rightarrow$ preço da força de trabalho = salário

$\mathrm{M} \rightarrow$ mais valia efetiva extraída em cada setor

$\mathrm{PP} \rightarrow$ Preço de produção

$\mathrm{ME} \rightarrow$ Mais valia extra extraída e transferida entre os produtores

MT $\rightarrow$ Mais valia total efetivamente apropriada por cada setor

$\mathrm{PM} \rightarrow$ Preço de mercado efetivamente praticado

$\mathrm{TL} \rightarrow$ Taxa de lucro sobre o capital total 
Registre-se que esses são resultados aproximados na medida em que haverá sempre diferença entre valores, preços de produção e preços de mercado, na medida mesmo em que estão se alterando, continuamente, canto as condições técnicas, quanto as relações econômicas, o quadro político, a luta de classes, a ação do Estado e de outras instituições.

No esquema anterior, não foi explicitada a relação essencial entre valores e preços, o que poderia conduzir à falsa ideia de que se assume aqui a ociosidade da teoria do valor tal como afirmam neoclássicos, como Samuelson, e neoricardianos. Ao contrário disso, neste ensaio a teoria de valor é fundamento necessário e imprescindível para uma compreensão crítica da realidade econômica capitalista.

Nesse sentido, cabe destacar os momentos centrais da relação entre valores e preços, do trabalho abstrato como substância de valor. Em primeiro lugar, lembre se que é atributo intransferível do trabalho vivo a capacidade de conservar valores pretéritos contidos no capital constante, $\mathrm{c}$, mediante sua transferência para os valores das mercadorias num processo que Marx chamou de depreciação. Também prerrogativa exclusiva da força de trabalho é a capacidade de criação de valores novos, de seu próprio valor, v, e a criação de valor excedente, mais valia, m. Assim, quando os capitalistas vão ao mercado e compram capital constante, c, a conservação desse valor, a possibilidade de no final do consumo produtivo desse capital, bastar para comprar novos elementos de capital constante, no mesmo valor que o inicial, é resultado da ação essencial e exclusiva da força de trabalho.

Um outro momento em que essa dimensão essencial da força de trabalho se manifesta, onde a massa de valores produzidos, a quantidade de trabalho materializado em valores de uso se faz decisiva, é no referente à produção e apropriação de lucros. Os capitalistas se apropriarão de lucro na quantidade total da mais valia gerada, isto é, do trabalho não pago apropriado pelos capitalistas. Daí que a soma total dos lucros será sempre igual à soma total da mais valia.

No esquema, anterior sintetizado no Quadro I, tomou-se uma certa relação de equilíbrio entre oferta e demanda. Havendo uma elevação da oferta e conservandose o suposto de que tal oferta encontrará demanda, segue-se que:

Quadro II: Oferta crescente

\begin{tabular}{c|c|c|c|c|c|c|c|c|c}
\hline & \multicolumn{4}{|c|}{ Circulação } & \multicolumn{4}{c|}{ Produção } & \multicolumn{2}{c}{ Circulação } \\
\hline Produtos & Preço inicial & C & V & M & PP & ME & MT & P.M. & TL = MT \\
\hline C+V \\
\hline A & $140 \$$ & $60 \$$ & $40 \$$ & 40 & $140 \$$ & 0 & 40 & $140 \$$ & $40 \%$ \\
B & $140 \$$ & $50 \$$ & $50 \$$ & 50 & $150 \$$ & -10 & 40 & $140 \$$ & $40 \%$ \\
C & $140 \$$ & $40 \$$ & $60 \$$ & 60 & $160 \$$ & -20 & 40 & $140 \$$ & $40 \%$ \\
\hline$\Sigma$ & $420 \$$ & $150 \$$ & $150 \$$ & 150 & $450 \$$ & -30 & 120 & $420 \$$ & $40 \%$ \\
\hline
\end{tabular}

Nesse caso, os mesmos elementos que foram aduzidos para explicar a permanência do produtor $C$, no caso de equilíbrio entre oferta e demanda, serão considerados aqui com a seguinte consequência: a permanência dos produtores $\mathrm{B}$ e $\mathrm{C}$ na indústria depende da capacidade deles de aumentarem suas mais valias absolu- 
tas e/ou da redução de salários o que, sobretudo, beneficiará o produtor A que poderá até ampliar seus lucros bastando para isto que reduza seus preços, ampliando assim sua fatia de mercado, em detrimento de $\mathrm{B}$ e $\mathrm{C}$, o que só é possível porque o esforço de permanência deles na indústria tem como resultado prático a redução do custo de reprodução da força de trabalho e/ou dos salários.

Num terceiro momento, considere-se a situação em que a demanda é crescente:

Quadro III: Demanda crescente

\begin{tabular}{c|c|c|c|c|c|c|c|c|c}
\hline & \multicolumn{3}{|c|}{ Circulação } & \multicolumn{4}{c|}{ Produção } & \multicolumn{3}{c}{ Circulação } \\
\hline Produtos & Preço inicial & C & V & M & PP & ME & MT & P.M. & TL = MT \\
\hline A & $160 \$$ & $60 \$$ & $40 \$$ & 40 & $140 \$$ & +20 & 60 & $160 \$$ & $60 \%$ \\
B & $160 \$$ & $50 \$$ & $50 \$$ & 50 & $150 \$$ & +10 & 60 & $160 \$$ & $60 \%$ \\
C & $160 \$$ & $40 \$$ & $60 \$$ & 60 & $160 \$$ & 0 & 60 & $160 \$$ & $60 \%$ \\
$\Sigma$ & $480 \$$ & $150 \$$ & $150 \$$ & 150 & $450 \$$ & +30 & 180 & $480 \$$ & $60 \%$ \\
\hline
\end{tabular}

Nessa terceira situação, o aumento da demanda faz com que haja uma elevação do valor social do produto, isto é, um aumento do tempo de trabalho socialmente necessário, configurando situação que Marx vai tratar de forma geral no contexto da discussão sobre a renda absoluta da terra, nos capítulos XLIV e XLV do livro III de O Capital.

Não se depreenda desses esquemas um algoritmo exato da transformação dos valores em preços. Na verdade, não há transformação dos valores em preços, não há uma separação rígida entre o momento de produção - valores - e o momento de circulação - preços. A produção e a circulação são esferas interagentes em que a informação de uma esfera - conjunto dos elementos que definem a concorrência (circulação) - determina a dinâmica concreta das formas de extração da mais valia (produção).

Isso ocorre porque se está considerando um processo em que as mudanças não são sincronizadas e nem absolutamente proporcionais, a igualdade entre a massa total de mais valia e a de lucros e a igualdade entre a taxa de lucro medida em termos de valor e a taxa de lucro medida em termos de preço, são tendências, são aproximações a uma realidade, o capitalismo, definitivamente infenso ao equilíbrio e à identidade.

Contudo, admitir a alteridade, o desequilíbrio, como centrais na dialética valores-preços não significa abrir mão do rigor, contentar-se com o casuístico. Rigorosamente, o que parece arrepiar os cultores do fetichismo da identidade e do equilíbrio, para manter a universalidade do argumento basta que se estabeleça um conjunto de relações sistemáticas entre as categorias em pauta de modo a garantir sua sistematicidade, isto é, as condições básicas da reprodutibilidade do sistema. No caso em pauta, trata-se de construir as relações teóricas básicas que garantam a reprodução capitalista. Essas relações teóricas incidirão, necessariamente, sobre os elementos do próprio processo de reprodução capitalista - capital constante, capital variável e mais valia. 
No referente ao capital constante, a condição básica capaz de garantir a reprodução do sistema é que o preço do capital constante $\mathrm{C}$ seja reproduzido mediante a ação do trabalho vivo, que a cada período de produção transferirá - descongelará uma parte do valor contido no capital constante numa fração proporcional à sua vida útil operacional, algebricamente:

$$
\mathrm{C}=\sum \mathrm{ci}_{\mathrm{i}=1, \ldots \mathrm{n}}
$$

O capital variável, utilizado para alugar força de trabalho, fonte de valor e mais valia, tem um preço que é igual à massa de salários. A reprodução básica do sistema estará assegurada mesmo com a flutuação do salário desde que no intervalo que vai de um mínimo, que é dado pelo mínimo de subsistência, a um máximo, que é o salário acima do qual a acumulação de capital fica comprometida. Esquematicamente:

$$
\text { Min. subs. } \leq \text { salário } \leq \text { Máx. }
$$

Finalmente, no referente à mais valia, a relação básica essencial é a que estabelece: 1) a mais valia é a fonte básica de todo excedente apropriado pelos capitalistas sob qualquer forma de renda - lucro, aluguéis, juros; 2) a soma total da renda capitalista é igual à soma total da mais valia. Algebricamente:

$$
\sum \mathrm{M}=\sum \mathrm{L}
$$

As três condições básicas de reprodução estabelecidas poderão não se verificar, ao menos temporariamente, isto é, $\mathrm{C}>\sum \mathrm{c}$; significando descapitalização; o salário poderá ser menor que o Min. subs. ou maior que o Máx. acarretando num caso a não reprodução da força de trabalho, noutro a redução do ritmo da acumulação; finalmente, $\Sigma \mathrm{M}<\sum \mathrm{L}$ na medida em que o capital burlar a equivalência nas trocas, isto é, quando, por exemplo, pagar salário menor que o mínimo de subsistência. De qualquer modo, estas situações, se se repetirem, comprometerão a continuidade do processo.

Trata-se, enfim, de apontar a existência das condições básicas de funcionamento da dialética entre valores e preços sem que isso signifique a fetichização do equilíbrio, mas a presença de faixas de vigência dos fenômenos, onde há lugar para a alteridade, para a ruptura, para a crise.

João Machado Borges Neto sintetiza a manutenção da centralidade do valor em sua relação com os preços e do absoluto rigor e coerência do procedimento de Marx, a partir da tese do sistema único temporal, da seguinte maneira: "Marx não carecia de transformar os valores do capital constante e do capital variável em preços de produção, porque estes valores são dados em dinheiro, e porque os valores dos meios de produção adquiridos pelos capitalistas, e dos meios de consumo adquiridos pelos trabalhadores, já haviam sido transformados em preços de produção em um momento anterior" (Neto, 1998, p. 81).

A grande "novidade" da abordagem do sistema único temporal, o que permite que ela supere as invalidações recorrentes ao chamado equívoco do "algoritmo da transformação dos valores em preços de Marx", é a redescoberta de que para Marx tanto o valor do capital constante, quanto o valor do capital variável, quanto a mais valia são quantidades de dinheiro. Dizem Freeman e Carchedi: 
"Ramos and Rodriguez, and McGlone and Kliman argue and explain that this is not only incoherent but incompatible with Marx's own presentation. In part the value transferred by constant capital is equal to the value as measured by the money advanced to purchase the elements of this capital. Likewise, the value of variable capital is measured by the money advanced to pay the labourer, not the value of the products she or he consumes. These two conclusions, amply supported by Marx's own writings, utterly invalidate the traditional refutation of Marx's transformation of value into price. They permit a further decisive development: a recuperation of money in Marx's analysis of value and price in particular, and economic movement in general" (Freeman e Carchedi, 1996, p. XI).

Esse novo aporte, essa afirmação da coerência e rigor da teoria marxista, trazida pela tese do sistema único temporal, permite que a teoria possa avançar sem que a cada momento seja obrigada a responder a falsas imputações. Há, ainda, muito o que fazer no campo marxista, sobretudo no referente à teoria da concorrência.

\section{CIRCULAÇÃO OU PRODUÇÃO?}

A tradição sraffiana, adotada amplamente, inclusive por quem se reclama marxista, entre outras consequências importantes sobre o conjunto da teoria econômica, implicou estabelecer uma rígida separação entre produção e distribuição, a qual se daria no plano da circulação e seria determinada, em última instância, pela luta entre capital e trabalho, enquanto a produção seguiria sendo o reino das relações técnicas. Esta "politização" da distribuição acaba sendo, por outro lado, uma "fetichização" da produção, tomada como espaço técnico, neutra, infensa à luta de classes. Ora, do ponto de vista de Marx, a luta de classes não tem espaços restritos, ela se manifesta em todos os planos da vida social. Não há razão para excluir a produção de sua ação. Na verdade, o processo de trabalho, isto é, a forma concreta de produção de valores de uso, é inteiramente condicionada pela dinâmica da luta de classes, seja ao materializar as estratégias de exploração do trabalho, seja ao contemplar as estratégias de resistência e luta dos trabalhadores.

De outro lado há os que, como João Bernardo, insistem na centralidade-hegemonia da produção transformando a esfera da circulação em mera coadjuvante de um processo definido, quase que inteiramente, no plano de produção - "no capitalismo, é devido à concorrência na produção que os produtos são socializados no mesmo processo por que são produzidos, antes portanto de alcançarem a esfera do mercado. Esta é meramente acessória, de antemão determinada na esfera da produção e, por isso, os mecanismos da circulação são neste modelo constituídos fundamentalmente pela repartição intercapitalista da mais valia, a qual decorre da concorrência na produção.” (Bernardo, 1991, p. 228).

Para Bernardo, teria sido o próprio Marx que teria induzido uma leitura que apontaria o mercado, como a única instância capaz de garantir a sociabilização do processo: "Para Karl Marx, a inter-relação econômica se estabeleceria no mercado; 
na esfera da produção, os bens apenas antecipariam o caráter social, em função de uma futura sociabilização na esfera da circulação”. (Bernardo, 1991, p. 228).

Num registro mais nuançado, também Sérgio Silva aponta os "descuidos” de Marx, em alguns trechos de O Capital, quando trata a circulação como momento separado e posterior ao da produção: "Esses efeitos de separação conduzem a uma ilusão sobre a possibilidade de conceber e, mais geralmente, tratar a circulação de modo isolado, como um momento posterior ao momento da produção, quando, na verdade, essa sequência é puramente lógica; na prática, circulação e produção são processos concomitantes”.

"Sem a preocupação de desculpar o grande mestre, cabe afirmar que os trechos de Marx possíveis de servirem de base a esse mal-entendido devem ser interpretados como 'descuidos', uma vez que já no primeiro parágrafo do primeiro capítulo do Livro III de O Capital, como se não bastasse o título do próprio Livro III, ele afirma que o seu objetivo é, através da consideração dos problemas particulares da circulação, tratar do processo de produção no seu conjunto”. (Silva, 1981, pp. 115-6).

Sérgio Silva tem razão quando aponta a impropriedade de se falar da realidade da produção anterior e isolada da realidade da circulação. Contudo, seu argumento - produção e circulação como processos concomitantes - não explicita, suficientemente, a estratégia conceitual de Marx, a presença nesse passo, absolutamente fundamental, da dialética. Falar que produção e circulação são concomitantes pode ser apenas uma justificativa para a utilização do sistema de equações simultâneas na "transformação dos valores em preços". O que o argumento que foi desenvolvido aqui procurou mostrar é que não há passagem dos valores aos preços, porque não há um momento real, isolado no tempo e no espaço, em que os valores gerados são levados ao mercado para adquirirem caráter social. Na verdade, a relação entre valores e preços não é binária. Não se trata de realizar as passagens/ transformações:

1) de valores a preços;

2) de produção para a circulação;

3) do trabalho individual para o trabalho social.

Na verdade, a lógica da construção de Marx pode ser pensada como baseada em tríades dialéticas: a primeira delas apresentada por Isaak Rubin e as duas outras desenvolvidas neste artigo.
1) 1) Trabalho universal $\rightarrow$ 2)
a) Trabalho Privado
b) Trabalho concreto
c) Trabalho complexo
d) Trabalho individual
II) 1) Circulaçăo $\rightarrow$
1II) 1) Preços $\rightarrow$
3) Circulação
3) Preços 
O que significa dizer que os atos privados de compra e venda, a exploração individual da força de trabalho, o caráter concreto, complexo, heterogêneo e individual do trabalho, tal como expostos por Rubin (Rubin, 1974, p. 180) são, na verdade, as manifestações necessárias e possíveis de um processo que é essencialmente universal, social, é totalidade, e que, no regime capitalista, só pode se manifestar de forma alienada, particular, finita.

\section{EM TEMPO}

Antes de dar por terminada a imprudente jornada, talvez se imponha a necessidade de sumarizar os pontos principais do que se procurou dizer.

1. Em primeiro lugar, registre-se que grande parte dos problemas, reais ou imaginários, atinentes à relação entre valores e preços, na obra de Marx, decorrem da reiterada incompreensão, que aliados e adversários, têm de sua metodologia. É amplamente conhecida a estrutura da exposição de O Capital, que avança do abstrato ao concreto, cuja dinâmica é dada por démarche lógico-genética, isto é, as categorias analíticas construídas por Marx não são nem pura facticidade-imediaticidade, nem pura abstração; são entidades ontológicas, unidades elementares de uma realidade - totalidade - em movimento, cuja expressão necessária é a contra dição. Trata-se, nesse sentido, de entender que a compreensão da obra de Marx, pressupõe, fortemente, levar a sério a dialética, dar-lhe consequência analítica.

No que interessa especificamente a este ensaio, trata-se de desfazer o equívoco interpretativo da teoria do valor de Marx. Essa teoria não está exposta no capítulo I, do livro I de O Capital.

Aquele é apenas o primeiro momento, lógica e geneticamente necessário, de afirmação de uma realidade, o valor, que só poder á ser apreendida quando se a reconstituir em sua trajetória histórica, de suas formas mais elementares abstratas, até a culminância de sua complexificação, quando estiver mergulhada na concreticidade dos vários capitais em disputa, no meio do torvelinho da concorrência.

O Capital, em seu livro I, realiza um primeiro movimento: o valor transita da situação inicial onde está considerado numa sociedade mercantil simples para os quadros de uma sociedade mercantil-capitalista, isto é, em que o trabalho já se separou dos meios de produção, que agora são monopolizados por uma outra classe. Contudo, essa sociedade continua sendo pensada abstratamente, o Capital aí, ainda, é uma totalidade abstrata-homogênea.

Marx indicou, mais de um a vez, que seu método impunha um caminho sistemático-inescapável do abstrato ao concreto, o que significa dizer que não é possível surpreender a totalidade complexa, a realidade pensada e apreendida pelo conceito, em todos os momentos da caminhada. Isto é, há uma progressão heurística das categorias analíticas em Marx. Na verdade, o que Marx mostrou, insistentemente, é que a aproximação do real é possível na medida em que se construa uma rede de mediações, em que as categorias analíticas mais simples, como o valor tal como aparece no capítulo 1 do livro I, vai ser enriquecido com a constelação de complexidades, metamorfoses, que a sua trajetória vai experimentando. 
Karel Kosik, em seu not ável Dialética do Concreto, descreveu este processo como a "odisséia" da categoria mercadoria, odisséia que teria seu desenlace quando o herói, transformado pela vivência e aspereza de sua experiência, voltasse ao seu lugar de origem metamorfoseado pelo que viveu e experimentou.

Se a odisséia homérica é o roteiro, a odisséia da mercadoria não o percorreu inteiramente. A mercadoria, que Marx acompanha e descreve, se multiplica, se enriquece, se complexifica, se desdobra, torna-se capital. Contudo, esse capital continua aquém de sua plena cons tituição porque continua genérico, abstrato, capital em geral, mesmo no livro III. Daí que, efetivamente, não se tenha realizado a metamorfose final: do capital em geral para os vários capitais; da concorrência abstrata para a concreticidade-alteridade da concorrência real, etc.

Não entender isso, buscar no capítulo I do livro I uma teoria completa do valor, ou ainda mais grave, tomar esse capítulo e associá-lo ao capítulo IX do livro III e extrair daí uma condenação ou aprovação da teoria do valor de Marx é de uma total impropriedade. A teoria do valor de Marx é, com certeza, a base de uma teoria dos preços, contudo, isso só faz sentido em Marx como parte de uma teoria do capital. Isso significa dizer que é no contexto de uma teoria do capital que se deve entender a teoria do valor e dos preços em Marx. E uma teoria do capital em Marx é, sobretudo, uma teoria da desigualdade, do conflito, do desequilíbrio, da alteridade.

2. É a explícita incompreensão desse aspecto do método de Marx - a teoria do capital como teoria da desigualdade - que norteou grande parte do que se escreveu sobre a relação entre valores e preços. Um exemplo disso está em Paul Sweezy, representante de uma importante tradição sobre essa questão, e que vê no respeito às condições de equilíbrio da reprodução simples a garantia de um método correto de transformação de valores em preços. Diz ele: "Se o processo usado na transformação de valores em preços for considerado satisfatório, não deve resultar na ruptura das condições de reprodução simples.( ...) O exame desse quadro revela que o método marxista de transformação resulta numa violação do equilíbrio da Reprodução Simples” (Sweezy, 1967, p. 142).

As condições básicas capazes de garantir a reprodução do sistema não são, historicamente, as do equilíbrio, seja no caso da reprodução simples, seja no caso da ampliada. As equações de equilíbrio da Reprodução Simples ou ampliada não são metas perseguíveis pelo capital, não são os similares marxistas do Equilíbrio geral. Aquelas equações, por suas condições restritíssimas, apontam, na verdade, para o quanto a economia capitalista é incompatível com o equilíbrio. Nesse sentido, não há propósito em impor à relação entre valores e preços a cláusula do equilíbrio na reprodução. A reprodução real, historicamente condicionada, está, sistematicamente, ocorrendo de forma desequilibrada, num processo em que as crises, as rupturas são consequências necessárias de uma realidade marcada pelo conflito, pela desigualdade.

3. Também importante é registrar que a materialização de uma solução adequada para a relação entre valores e preços, depende do desenvolvimento de uma teoria da concorrência, isto é, de uma teoria que incorpore as estruturas oligopólicas e seus mecanismos de formação de preços e diferenciação de taxas de lucro; o sistema financeiro e sua pletórica presença contemporânea; a expansão de eco- 
nomias não-capitalistas, baseadas em formas comunitárias, cooperativas, familiares etc., de propriedade e gestão e circuitos não-capitalistas de produção e circulação; o Estado e a luta política da sociedade civil, sua organização em sindicatos, associações, partidos etc.

\section{REFERÊNCIAS BIBLIOGRÁFICAS}

BERNARDO, João. Economia dos conflitos sociais. São Paulo, Cortez, 1991.

BÔHM-BAWERK, E. "La conclusión del sistema de Marx" in Economia Burguesa y Economia Socialista. Trad. esp., Buenos Aires, Cuadernos P y P, n” 49, 1974.

BORTKIEWICZ, Ladislaus von. "Contribuición a una retificación de los fundamentos de la construcción teórica de Marx en el volúmen III de El Capital” in Economia Burguesa y Economia Socialista, op. cit.

FREEMAN, Alan e CARCHEDI, Guglielmo. (orgs.). Marx and Non-Equilibrium Economics. UK, USA, Edward Elgar, 1996.

HILFERDING, Rudolf. "La Crítica de Bôhm Bawerk” in Economia Burguesa y Economia Socialista, op. cit.

LUKÁCS, Georg. Conversando com Lukács. Trad. port., Rio de Janeiro, Paz e Terra, 1969.

MARX, Karl. O Capital. Trad. port., Livro I, Rio de Janeiro, Civilização Brasileira, 1968. MARX, Karl. O Capital. Trad. port. Livro III, Rio de Janeiro, Civilização Brasileira, 1974.

MARX, Karl. “Glosas Marginales al Tratado de economia e política de Adolph Wagner” in ARICÓ, José (org.). Estudios sobre El Capital. Trad. esp., México, Espanha, Argentina, Colômbia, Siglo XXI, 1977.

NETO, João Machado Borges. "O Sistema Único Temporal: uma nova abordagem da transformação dos valores em preços de produção” in Revista ANPEC, n 3, 1998.

NETO, João Machado Borges. A Transformação dos Valores em Preços de Produção em um Sistema Único Temporal. Dissertação de Mestrado, PUC/SP, 1997.

ROSDOLSKY, Roman. Genesis y Estructura de El Capital de Marx. Trad. esp., México. Siglo XXI, 1978.

ROSDOLSKY, Roman. "La significación de El Capital para la investigación marxista contemporánea” in Leyendo El Capital. Trad. esp., Madrid, Fundamentos, 1972.

RUBIN, Isaak I. Ensayos sobre la Teoria Marxista del Valor. trad. esp., Buenos Aires, Siglo XXI, 1974. SILVA, Sérgio. Valor e Renda da Terra. São Paulo, Polis, 1981.

STEEDMAN, Ian. Marx, Sraffa y el problema de la Transformación. Trad. esp., México, FCF, 1985.

SWEEZY, Paul. Teoria do Desenvolvimento Capitalista. Trad. port., Rio de Janeiro, Zahar, $2^{\mathrm{a}}$ edição, 1967. 